\title{
Corrosion behaviour of Ni-P-SiO2 electroless composite coating
}

\author{
Su-Yan TIAN ${ }^{\mathrm{a}}$, Jun MA ${ }^{\mathrm{b}}$, Rong-Jian YING $^{\mathrm{c}}$ Shan-Liang MU ${ }^{\mathrm{d}}$
}

School of Chemistry and Chemical Engineering, Linyi University, 276000, China

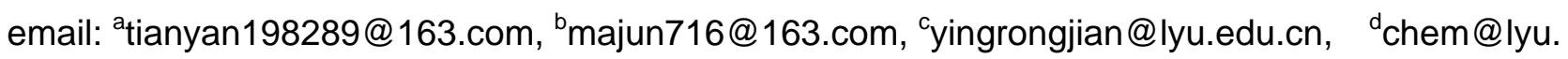
edu.cn

*Jun MA

Keywords: electroless plating; corrosion; composite coating

\begin{abstract}
In this paper, the protective electroless $\mathrm{Ni}-\mathrm{P} / \mathrm{SiO}_{2}$ on iron substrate were successfully prepared. The prepared $\mathrm{Ni}-\mathrm{P} / \mathrm{SiO}_{2}$ electroless composite coating were characterized for morphology, microstructure. The anticorrosion properties of the $\mathrm{Ni}-\mathrm{P} / \mathrm{SiO}_{2}$ coating in $10 \mathrm{wt} . \% \mathrm{HCl}$ solution were evaluated by immersion tests, SEM and EDS at ambiance temperature. The results revealed that the $\mathrm{SiO}_{2}$ concentration in the bath and heat treatment can influence the corrosion protection performance of electroless deposited $\mathrm{Ni}-\mathrm{P} / \mathrm{SiO}_{2}$ coatings. The corrosion resistance of $\mathrm{Ni}-\mathrm{P} / \mathrm{SiO}^{2}$ coating increases initially and decreases afterwards with the sustained increasing of immersion time in $\mathrm{HCl}$ solution. The $\mathrm{Ni}-\mathrm{P} / \mathrm{SiO}_{2}$ electroless composite coating can afford better corrosion protection for magnesium alloy substrate compared with Ni-P coating
\end{abstract}

\section{Introduction}

It is well known that the corrosion problem of refining equipments in chemical industry becomes more and more serious, especially the heat-exchangers[1,2]. Generally different carbon steels are chosen to produce the heat-exchangers due to their low price. However, the corrosion rates of these heat-exchangers are very fast because of their severe application environment with acid or alkaline. Thus, choosing reliable materials and protective methods have attracted more and more attention.

Autocatalytic electroless plating technology has been invented to improve the corrosion resistance of chemical industry. High phosphorus chemical plating Ni-P coating has extensive application in the field of chemical industry due to Its high hardness, good mechanical properties and excellent corrosion resistance [3-6]. However, the P content over 8 wt.\% shows the amorphous state structure of Ni-P coating [7]. The amorphous Ni-P coating has no defects such as dislocations and grain boundary. And it is easy to form a uniform passive film on the coating surface, which can improve the corrosion resistance of coating effectively. A major disadvantage of this coating at present is that its surface has many microporous, which are easy to become the corrosion source and lead to the damage of equipments finally [8].

In recent years, electroless composite plating method has attracted a lot of interesting [9-12]. Due to their excellent performance, the nano-particulates are used as reinforcing phase. The incorporation of nanoparticular within Ni-P electroless composite plating greatly improved their performance. Using as reinforcing phase, $\mathrm{SiO}_{2}$ nano-particulates attracted tremendous interests in research community. In this paper, $\mathrm{Ni}-\mathrm{P} / \mathrm{SiO}_{2}$ composite coating was prepared. The corrosion resistance of $\mathrm{Ni}-\mathrm{P}-\mathrm{SiO}_{2}$ coating was evaluated.

\section{Materials and methods}

\section{Sample preparation.}

The iron alloys substrate contained (wt.\%) 93.54\% Fe, 0.34\% Mn, 3.64\% C and 2.47\% O. In order to make substrate same surface roughness and ready for coating process, the substrate materials were polished up to grit silicon carbide paper. Iron alloys samples of dimensions $30 \mathrm{~mm} \times 15 \mathrm{~mm} \times 2 \mathrm{~mm}$ were suspended on nylon wire and ultrasonically degreased in acetone, subsequently cleaned in an alkaline solution containg $45 \mathrm{~g} \cdot \mathrm{L}^{-1} \mathrm{NaOH}$ and $8 \mathrm{~g} \cdot \mathrm{L}^{-1} \mathrm{Na}_{3} \mathrm{PO}_{4} \cdot 3 \mathrm{H}_{2} \mathrm{O}$ at $60{ }^{\circ} \mathrm{C}$ for $15 \mathrm{~min}$, then etched in a solution of $6 \mathrm{wt}$.\% $\mathrm{HCl}$ solution for a duration of $30 \mathrm{~s}$. The sample 
were rinsed using distilled water after different steps of the pretreatment process. Following the pretreatment stage, the sample were immersed in electroless bath.

The composition and operation conditions of electroless plating Ni-P was as follows: Nickel sulfate hexahydrate $26.7 \mathrm{~g} \cdot \mathrm{L}^{-1}$, Sodium hypophosphite $20 \mathrm{~g} \cdot \mathrm{L}^{-1}$, Sodium acetate $17 \mathrm{~g} \cdot \mathrm{L}^{-1}$, Lactic acid $12.09 \mathrm{~g} \cdot \mathrm{L}^{-1}$, Propionic acid $4.95 \mathrm{~g} \cdot \mathrm{L}^{-1}$, Surfactants $1 \mathrm{mg} \cdot \mathrm{L}^{-1}$, and Potassium iodide $1 \mathrm{mg} \cdot \mathrm{L}^{-1}$. The initial $\mathrm{pH}$ value of plating bath was adjusted ammonia solutions to 5-6. The temperature of the plating bath was controlled within $80^{\circ} \mathrm{C}$ using a ditally controlled thermostat. In order to produce a composite coating, the pre-made concentrated plating bath containing $2 \mathrm{~g} \cdot \mathrm{L}^{-1}$ solid $\mathrm{SiO}_{2}$ particles (0.4-0.6 $\mu \mathrm{m}$ in size) was carefully added dropwise to the above mentioned electroless palting bath over $1 \mathrm{~h}$ and uniformly dispersed in the bath using ultrasonic.

\section{Corrosion experiment.}

The corrosion behavior was characterized by immersion tests at ambiance temperature in 3 mol· $\mathrm{L}-1 \mathrm{HCl}$ solution. The samples for the corrosion evaluation were washed with distilled water and dried with warm flowing air. Corrosion macro-morphology was examined using scanning electron microscopy at different time after immersion.

\section{Characterization of Composite Coating.}

The composite coating was characterized by Scanning Electron Microscopy (SEM, JSM-5610LV) and Electron Diffraction Spectrum (EDS, Inca energy) techniques.

\section{Results and discussion}

The element of iron alloy substrate and $\mathrm{Ni}-\mathrm{P} / \mathrm{SiO}_{2}$ coating was analyzed by EDS. Analytical spectra and chemical composition of substrate and composite coating were obtained. The results are shown in Fig.1. The results show that the content of phosphorus in $\mathrm{Ni}-\mathrm{P} / \mathrm{SiO}_{2}$ coating is about 8 weight percent. The composite coating can be classified as medium phosphorus electroless nickel. The contents of $\mathrm{O}$ and $\mathrm{Si}$ in $\mathrm{Ni}-\mathrm{P} / \mathrm{SiO}_{2}$ coating are about 7 and 6 respectively. The results can be used to predict existence of $\mathrm{SiO} 2$ in the $\mathrm{Ni}-\mathrm{P} / \mathrm{SiO}_{2}$ coating.

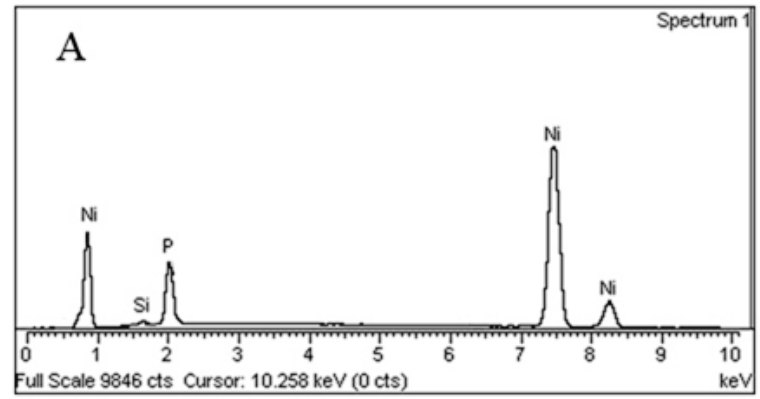

\begin{tabular}{c|c}
\hline Element & Weight\% \\
$\mathrm{O}$ & 7.06 \\
$\mathrm{P}$ & 7.85 \\
$\mathrm{Si}$ & 6.18 \\
$\mathrm{Ni}$ & 78.91 \\
Totals & 100.00 \\
\hline
\end{tabular}

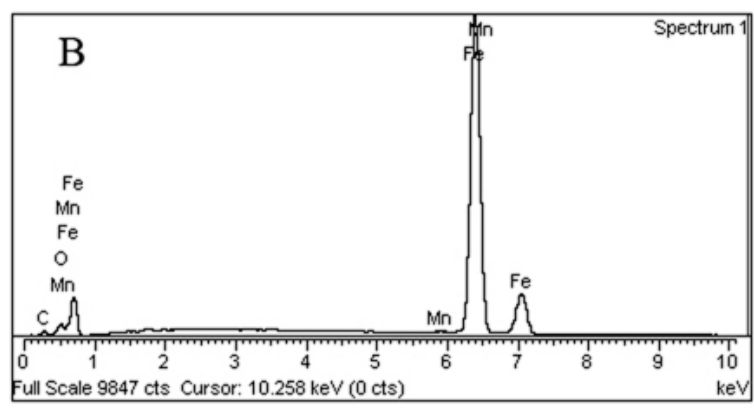

\begin{tabular}{c|c}
\hline Element & Weight\% \\
$\mathrm{C}$ & 3.64 \\
$\mathrm{O}$ & 2.47 \\
$\mathrm{Fe}$ & 93.55 \\
$\mathrm{Mn}$ & 0.34 \\
Totals & 100.00 \\
\hline
\end{tabular}

Fig.1 EDS spectra and chemical composition of the iron substrate and $\mathrm{Ni}-\mathrm{P} / \mathrm{SiO}_{2}$ electroless deposited coating (A iron substrate, $\mathrm{B}$ Ni-P-SiO ${ }_{2}$ )

Fig.2 shows SEM micrographs of electroless deposited Ni-P and $\mathrm{Ni}-\mathrm{P} / \mathrm{SiO}_{2}$ composite coating on iron alloys substrate. It can be seen that the surface of Ni-P coating shows a typical spherical nodular structure with good uniformity and dense coverage. The $\mathrm{Ni}-\mathrm{P} / \mathrm{SiO}_{2}$ composite coating exhibits coarse nodular structure due to the codeposition of $\mathrm{SiO}_{2}$ particle. It can also be observed that the number of these nodules in the $\mathrm{Ni}-\mathrm{P} / \mathrm{SiO}_{2}$ coating was more than that in the Ni-P coating, indicating that the $\mathrm{Ni}-\mathrm{P} / \mathrm{SiO} 2$ composite coating was more compact than the electroless Ni-P 
coating. In the process of electroless composite plating, the addition of $\mathrm{SiO}_{2}$ particles can increase the catalytic active sites of the matrix surface and act as the nucleation center. The deposition of nickel phosphorus alloy will wrap the $\mathrm{SiO}_{2}$ particle. The $\mathrm{SiO}_{2}$ particles adsorption randomly on the sample surface, and some parts of the nodule boundaries are covered by the $\mathrm{SiO}_{2}$ powders just adsorbed at the boundaries. Thus, the incorporation of $\mathrm{SiO}_{2}$ particles in Ni-P coating leading to the more nodules and more apparent roughness of $\mathrm{Ni}-\mathrm{P} / \mathrm{SiO}_{2}$ coating than those $\mathrm{Ni}-\mathrm{P}$ coating.
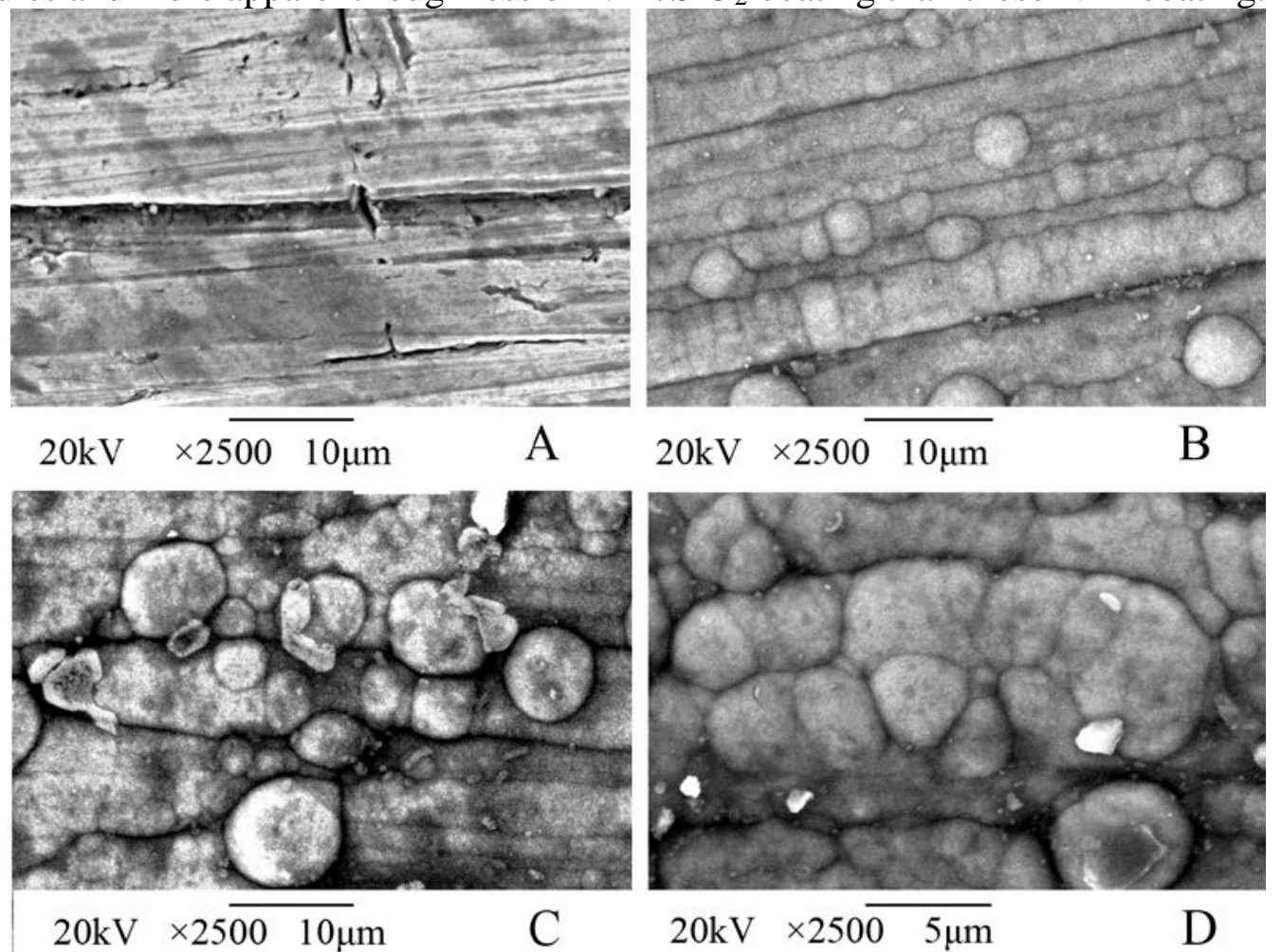

Fig.2 SEM micrographs of substrate and electroless deposited coating (A iron substrate, B Ni-P coating, $\mathrm{C}$ and $\mathrm{D} \mathrm{Ni}-\mathrm{P} / \mathrm{SiO}_{2}$ coating)

Fig. 3 shows the SEM images of the substrate and coating. A transformation of morphology was observed. In Fig.3, SEM morphology A and B were iron substrate before and after immersion in $\mathrm{HCl}$ solutions. After immersed in $\mathrm{HCl}$ solution, the iron substrate was corroded rapidly, and the surface of substrate was not smooth and regular. SEM morphology C and D were Ni-P coating before and after immersion in $\mathrm{HCl}$ solutions. During the corrosion process, Ni-P coating was destroyed, allowing easy access of $\mathrm{H}+$ and $\mathrm{Cl}$ - ions to penetrate the coating and interact with the iron alloy substrate.

Compared with iron substrate and Ni-P coating, the smoother surface shown by the $\mathrm{Ni}-\mathrm{P} / \mathrm{SiO}$ indicated the protective behavior of the Ni-P-SiO 2 coating against corrosion. SEM images of the electroless $\mathrm{Ni}-\mathrm{P} / \mathrm{SiO}_{2}$ coating before and after immersion in $\mathrm{HCl}$ solutions. The $\mathrm{Ni}-\mathrm{P} / \mathrm{SiO}_{2}$ composite coating before immersion in the $\mathrm{HCl}$ solution showed that the incorporated particles are evenly distributed in the composite coating and are firmly bonded to the substrate with Ni content of $79 \%$. The micrographs of the $\mathrm{Ni}-\mathrm{P} / \mathrm{SiO}_{2}$ coating upon immersion in $10 \mathrm{wt} . \% \mathrm{HCl}$ solution showed that the composite coating was less compact and loosely bonded to the substrate, compared to the coatings before the corrosion process. 

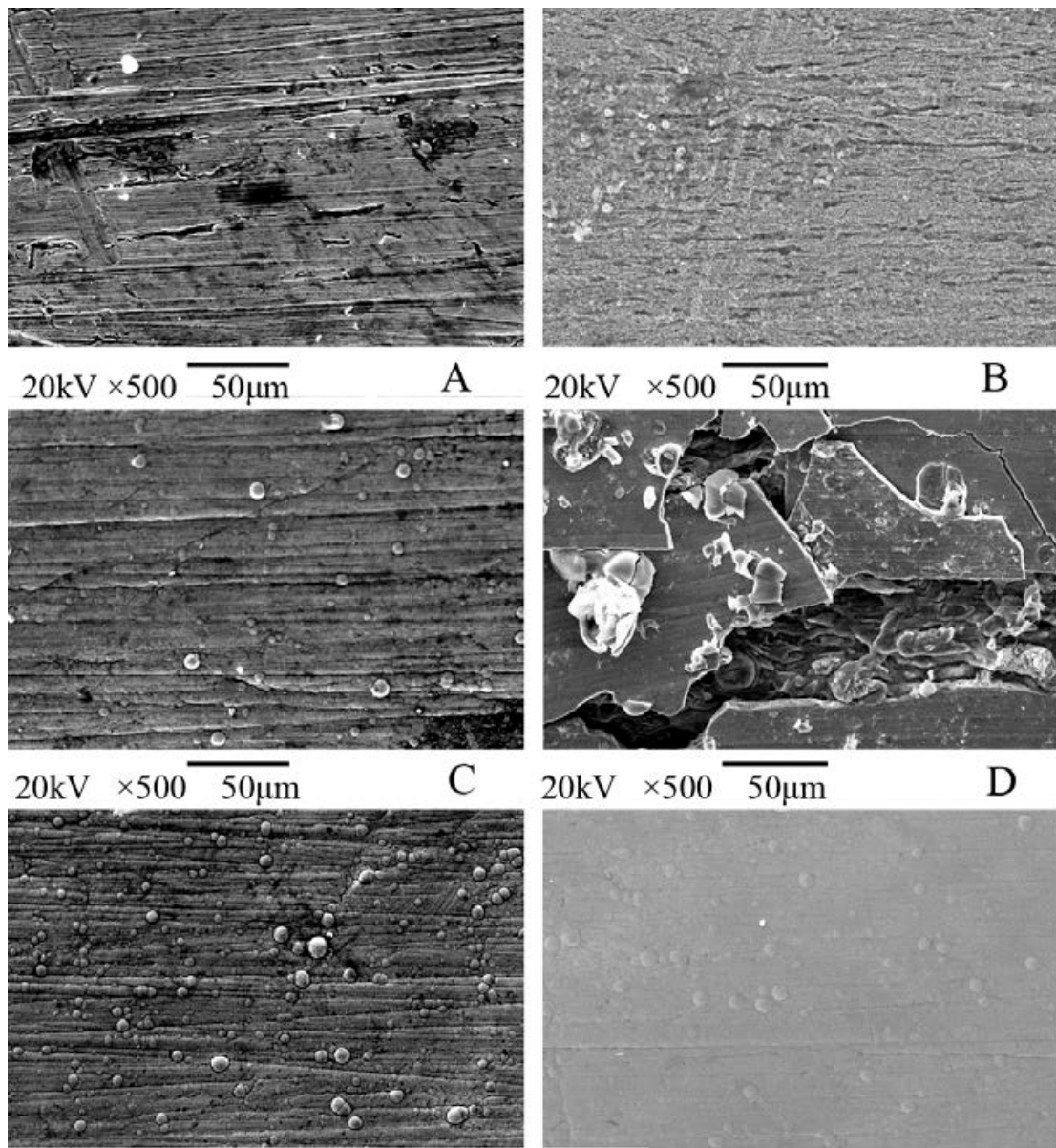

$20 \mathrm{kV} \times 500 \overline{50 \mu \mathrm{m}}$

$\mathrm{D}$

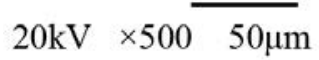

$\mathrm{E}$

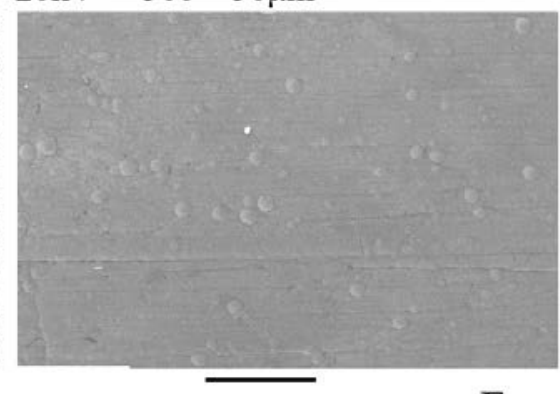

Fig.3 SEM micrographs of substrate and electroless deposited coating in 10wt.\% HCl solution.

(A and $\mathrm{B}$ iron substrate, $\mathrm{C}$ and $\mathrm{D} \mathrm{Ni}-\mathrm{P}$ coating, $\mathrm{E}$ and $\mathrm{F} \mathrm{Ni}-\mathrm{P} / \mathrm{SiO}_{2}$ coating)

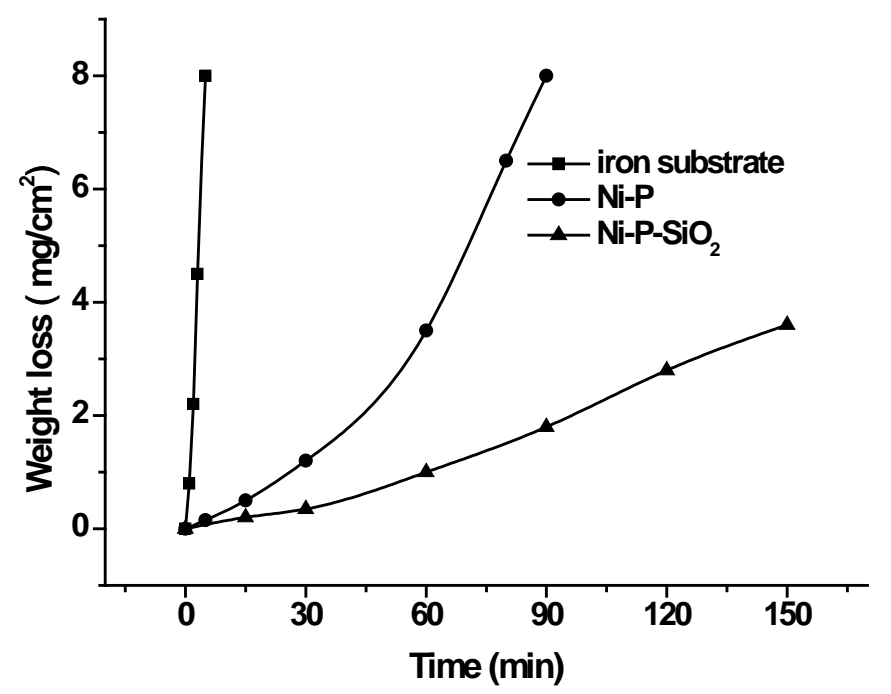

Fig.4 Corrosion quantity in the $10 \mathrm{wt} . \% \mathrm{HCl}$ solutions with time

The corrosion of $\mathrm{Ni}-\mathrm{P} / \mathrm{SiO}_{2}$ composite coating in $10 \mathrm{wt} . \% \mathrm{HCl}$ solution at different time were shown in Fig.4. From the corrosion behaviors of iron substrate, Ni-P and Ni-P/SiO 2 coating in $\mathrm{HCl}$ solution, it was observed that the corrosion rates were different for the sample. The corrosion rates order was iron substrate $>\mathrm{Ni}-\mathrm{P}>\mathrm{Ni}-\mathrm{P} / \mathrm{SiO}_{2}$. The $\mathrm{Ni}-\mathrm{P} / \mathrm{SiO}{ }_{2}$ composite coating had the best corrosion resistance in $\mathrm{HCl}$ solution. The decreased corrosion rate that was obtained from the weight loss seem to indicate that the corrosion resistance is related to increase of the $\mathrm{SiO}_{2}$ particle in the coating. 


\section{Conclusion}

Using $\mathrm{SiO}_{2}$ nano-particulates as reinforcing phase, $\mathrm{Ni}-\mathrm{P} / \mathrm{SiO}_{2}$ composite coating was prepared. The micrographs and composition of $\mathrm{Ni}-\mathrm{P} / \mathrm{SiO}_{2}$ were analyzed by SEM and EDS. The corrosion performance of coating was also evaluated. Compared with iron substrate and Ni-P coating, the $\mathrm{Ni}-\mathrm{P} / \mathrm{SiO}_{2}$ composite coating exhibits coarse nodular structure due to the codeposition of $\mathrm{SiO}_{2}$ particle. However, the corrosion resistance of $\mathrm{Ni}-\mathrm{P} / \mathrm{SiO}_{2}$ is better than $\mathrm{Ni}-\mathrm{P}$ coating.

\section{References}

[1] Mingan Chen, Nan Cheng, Yanchun Ou, Juming Li, Corrosion performance of electroless Ni-P on polymer coating of MAO coated AZ31 magnesium alloy, Surface and Coating Technology, 2013, 232: 726-733.

[2] Jothi Sudagar, Jiangshe Lian, Wei Sha, Electroless nickel, alloy, composite and nano coatings A critical review, Journal of Alloys and Compounds, 2013, 571: 183-204.

[3] Kong Dejun, Wang Jinchun, Fu Guizhong, Liu Hao, Friction and wear performances of Ni-P coatings by chemical plating after crystallization treatment, Rare metal materials and engineering, 2015, 44: 1314-1319.

[4] K. Hari Krishnan, S. John, K.N. Srinivasan, J. Praveen, M. Ganesan, P.M. Kavimani, An overall aspect of electroless Ni-P depositions- A review article, Metallurgrcal and materials transactions A, 2006, 37: 1917-1926.

[5] P. Peeters, G. v.d. Hoorn, T. Daenen, A. kuroswski, G. Staikov, Properties of electroless and electroplated Ni-P and its application in microgalvanics, Electrochimica Acta, 2001, 47: 161-169

[6] Changdong Gu, Jianshe Lian, Guangyu Li, Liyuan Niu, Zhonghao Jiang, High corrosion-resistant Ni-P/Ni/Ni-P multilayer coatings on steel, Surface and coating technology, 2005, 197: 61-67.

[7] Zahra Sharifalhoseini, Mohammad H. Entezari, Enhancement of the corrosion protection of electroless Ni-P coating by deposition of sonosynthesized $\mathrm{ZnO}$ nanoparticles, Applied surface science, 2015, 351: 1060-1068.

[8] Zuwei Yin, Fuyi Chen, Effect of nickel immersion pretreatment on the corrosion performance of electroless deposited Ni-P alloys on aluminum, Surface and coating technology, 2013, 228: 34-40.

[9] Mohammad Islam, Muhammad Rizwan Azhar, Narjes Fredj, Influence of SiO2 nanoparticles on hardness and corrosion resistance of electroless Ni-P coating, Surface and coating technology, 2015, 261: 141-148.

[10] R. Soleimani, F. Mahboubi, S.Y. Arman, M. Kazemi, A. Maniee, Development of mathematical model to evaluate microstructure and corrosion behavior of electroless Ni-P/nano-SiC coating deposited on 6061 aluminum alloy, Journal of industrial and engineering chemistry, 2015, 23: $328-337$

[11] Chunyang Ma, Feifei Wu, Yumei Ning, Fafeng Xia, Yongfu Liu, Effect of heat treatment on structure and corrosion characteristics of electroless Ni-P-SiC nanocomposite coatings, Ceramics International, 2014, 40: 9279-9284.

[12] T.R. Tamilarasan, R.Rajendran, G. Rajagopal, J. Sudagar, Effect of surfactants on the coating properties and corrosion behavior of Ni-P-nano-TiO2 coating, Surface and coating technology, 2015, 276: 320-326. 